\title{
Occupational and environmental health hazards associated with food processing and the use of personal protective equipment: A case study of Gari processing in southern Ghana
}

\author{
Benedicta Y. Fosu-Mensah* iD \\ Institute for Environment and Sanitation Studies (IESS), College of Basic and Applied \\ Sciences, University of Ghana, Ghana \\ Derek Fiifi Adabie \\ Department of Crop Science, University of Ghana, Legon, Accra, Ghana \\ Paa-Nii T. Johnson \\ Dept of Agro-processing Technology and Food Biosciences, CSIR- College of Science and \\ Technology Box M.20. Accra, Ghana. \\ Michael Mensah \\ Department of Business Administration, University of Professional Studies, Accra (UPSA), \\ Ghana \\ *Corresponding author. Email: yayramensah@staff.ug.edu.gh
}

\section{Article Info}

https://doi.org/10.31018/

jans.v13i1.2520

Received: January 28, 2021

Revised: March 3, 2021

Accepted: March 6, 2021

\section{How to Cite}

Fosu-Mensah, B. Y. et al. (2021). Occupational and environmental health hazards associated with food processing and the use of personal protective equipment: A case study of Gari processing in southern Ghana. Journal of Applied and Natural Science, 13(1): 230 - 237. https://doi.org/10.31018/jans.v13i1.2520

\begin{abstract}
The processing of cassava into different staple foods, including gari, comes with occupational and environmental hazards. This research aimed at assessing the awareness of occupational health hazards associated with the processing of cassava (Manihot esculenta) into Gari, environmental impact and factors that influence the wearing of personal protective equipment. Ninety (90) Gari producers were randomly selected from Awutu Senya, Central Tongu and Ayensuano Districts of Ghana and interviewed using structured and semi-structured questionnaire. Results revealed that Gari producing industry was dominated by women $(78.9 \%)$. The majority of cassava processors in the study area were aware of health hazards associated with the production of gari. However, most did not take measures to reduce or mitigate exposure to health risk. The Gari industry was less attractive to people above 60 years (8.9\%). Training on occupational safety and health risk was low among processors. The usage of personal protective equipment (PPE) by processors was low. Only 3.3\%, 16 and $17.8 \%$ used footwear, working gear and coat, respectively, during processing. Factors that influenced processors' decision to use PPE included years of experience in processing, knowledge of health risk associated with the processing of cassava into Gari, awareness of protective equipment and a visit to health facility relating to condition sustained at work. Producers were aware of the environmental effects of Cassava-mill effluent but did not treat effluents before discharge into the environment. Some environmental effects of mill cassava effluent identified by the gari producers were; reduction in soil productivity, destruction of vegetation cover, the killing of trees and bad odour. The low level of education and training accounted for the low usage of PPEs.
\end{abstract}

Keywords: Cassava effluent, Gari processing, Health risk, Environment, Protective equipment

\section{INTRODUCTION}

Cassava (Manihot esculenta, Crantz) is a starchcontaining root crop, traditionally processed into several food staples and serve as major sources of calories for people in Sub-saharan Africa (Ogunyinka and Oguntuas, 2020). Cassava is unfortunately highly perishable because of its high moisture content and therefore be- gins to degenerate, usually two or three days after harvest. The roots contain about $70 \%$ moisture, making it difficult and expensive to transport it (Morgan and Choct 2016). Additionally, fresh cassava contains cyanide making it too toxic to humans and animals in the raw state. When processed, the cyanide contents of cassava is drastically reduced. Processing of the tubers is normal traditional practices used to turn cassa- 
va into useful edible food staples. In Ghana, the majority of cassava tubers are processed into several food staples like 'gari', cassava dough (agbelima), cassava flour and starch. The tubers are also prepared into readily eaten foods such as 'fufu', 'kokonte' and 'attieke' (also spelt 'acheke'). Gari is one of the most shelf-stable cassava-processed foods, mostly done on a small scale, with $8-10 \%$ moisture ( James et al., 2012).

The key processing steps involved in gari production (peeling, washing, grating, pressing and fermenting, dewatering, sieving and frying) as well as the inefficient accompanying handling practices of the byproducts (for example, the peels and spent liquid waste), usually present several occupational-related hazard conditions to the small-scale gari producers. These health hazards include inhalation of cyanide and smoke (Frca and Frca Fficm (2015). Adenugba and John (2014) reported knife cuts, ergonomic hazards, eye irritations, and exposure to intense heat and smoke as some additional occupational hazards associated with cassava processing into gari.

The generation of the spent liquid waste, derived from the dewatering stage during the processing of cassava into gari is one of major concern. At most sites where cassava is being processed into gari, this spent liquid waste is allowed to flow into the surrounding environment, usually into small dugouts close by the processing sites, without any conscious attempt to treat and/or redirect it. This indiscriminate and continuous disposal could have dire consequences on the environment (Obueh and Odesiri-Eruteyan, 2016).

In Ghana producers of gari, work in less-ventilated sheds and often exposed to high levels of hydrogen cyanide $(\mathrm{HCN})$ that are evaporating during the frying of the cassava grits (Oyinkan et al., 2016). Skin irritation (itchiness) as a result of cyanide present in the cassava coming in contact with the skin (Adenugba and John, 2014) have been reported. Graham and Traylor (2020) reported that the exposure to cyanide inhibits the use of oxygen by the human cells resulting in death of these cells. Smoke from the fire also irritates the eyes, nose and throat (Juntarawijit and Juntarawijit (2019) of the processor, causing difficulty in breathing ( Neghab et al., 2017). Similarly, the heat from the fire results in increased irritability and loss of concentration and the ability to do mental tasks (CCOHS, 2014).

Environmental problems are associated with the indiscriminate discharge of cassava effluent. These include eutrophication of slow moving water leading to oxygen depletion and death of aquatic life (Omotosho and Amori 2015). Cassava effluent is also reported to inhibit seed germination and seedling growth of Zea mays, Sorghum bicolor and Pennisetum americanum as well as the death of plants with continuous release into the environments (Akpokodje et al., 2018). Processing of cassava into gari is mostly done in the southern part of Ghana. However, the effluents from mash cassava are improperly or dangerously disposed off, with little disregard for safety measures, which exposes processors and the environment to health risks. Unfortunately, there is little documented information on occupational exposure, safety measures, and environmental impact of cassava processing into gari in these parts of Ghana. This study therefore aimed at assessing the potential occupational health risks, environmental effects and the pattern of use of personal protective equipment (PPE) during the processing of cassava into gari in southern parts of Ghana.

\section{MATERIALS AND METHODS}

\section{Study area and data collection}

A survey was conducted in three cassava producing districts in Ghana: the Awutu-Senya, Central Tongu and Ayensuano Districts; located in the Central, Volta and Eastern Regions of Ghana, respectively. These districts were selected based on their levels of cassava production and processing. Each district was segmented into three clusters, from which respondents were randomly sampled. A pre-tested semi-structured questionnaire was used to investigate the awareness of occupational and environmental health hazards associated with the processing of Cassava (Manihot esculenta,) into Gari, and factors that influence the wearing of personal protective equipment. Ninety (90) small/mediumscale gari producers served as respondents (ten (10) from each cluster)

\section{Data analysis}

The statistical package for social sciences (SPSS) software version 17 was used to analyse the mean of responses. The probit model was employed due to the nature of the decision variable; whether gari producers wore protective equipment during processing or otherwise. The probit model is the most appropriate analysis tool for a dichotomous outcome $(1=$ Yes and $0=$ No). The probit distribution has the advantage in the analysis of dichotomous outcome variable, which is extremely flexible. The probit model was used to assess the operational habits exhibited by gari producers and factors that influence the value addition of effluent.

\section{RESULTS}

\section{Demographic information of respondents}

Table 1 presents the demographic characterization of the respondents in the study area. The results showed that females dominated $(78.9 \%)$ in the gari producing industry, with only $21.1 \%$ being males. The majority (37.8\%) of the respondents had ages between $40-49$ years. A total of $60 \%$ respondents' age fell within $30-$ 
Fosu-Mensah, B. Y. et al. / J. Appl. \& Nat. Sci. 13(1): 230 - 237 (2021)

\begin{tabular}{llll}
\hline Table 1. Demographic information of gari producers in southern Ghana. & \\
\hline Variable & Description & Frequency & Percentage (\%) \\
\hline \multirow{2}{*}{ Gender } & Male & 19 & 21.1 \\
& Female & 71 & 78.9 \\
& $20-29$ & 12 & 13.3 \\
& $30-39$ & 20 & 22.2 \\
Age & $40-49$ & 34 & 37.8 \\
& $50-59$ & 16 & 17.8 \\
& $60-69$ & 6 & 6.7 \\
& $\geq 70$ & 2 & 2.2 \\
& None & 28 & 31.1 \\
Formal Education & Primary School & 26 & 28.9 \\
& Middle School/ JHS & 27 & 30.0 \\
& SHS & 7 & 7.8 \\
& Tertiary & 2 & 2.2 \\
\hline
\end{tabular}

49 years; whereas, $2.2 \%$ were 70 years and above. The respondents' education characteristic indicated that the majority $(68.9 \%)$ of the respondents had formal education. However, only $10 \%$ of the respondents had secondary and tertiary education. About $31.1 \%$ of the respondents had no formal education.

Respondents experience in the processing of cassava into gari

Results showed that all respondents (100\%) produced gari for commercial purposes (Table 2). In addition, the majority $(91.1 \%)$ of respondents were engaged in other economic activities, with only $8.9 \%$ of the respondents processing cassava into gari as their sole occupation. The livelihood diversification of gari producers enabled them to generate multiple streams of income to sustain their households. Majority of the respondents (84.6\%) had 6 years and above experience in gari processing with $44.5 \%$ haven experience of $6-15$ years (Fig. 1). This clearly showed that majority of gari producers in the study area had adequate experience in processing. It is therefore likely that their adoption levels of technologies such as improved stove will be high. Results showed that $33.3 \%$ of the respondents processed an average of $100 \mathrm{~kg}-250 \mathrm{~kg}$ of cassava mash per week (Table 2) with only $3.3 \%$ processing $900-1050 \mathrm{~kg}$ per week.

\section{Gari producers' perception and training on occupational health risk}

The majority $(97.8 \%)$ of the processors perceived gari production to be hazardous to their health with only $2.2 \%$ perceiving otherwise. However, only $16.7 \%$ wore the dress that protected their hands and legs. The gari producers identified some health hazards included inhalation of smoke, intense heat from the furnace, and boulder accident. Results indicate that only $5.6 \%$ of respondents had received some training on ways to mitigate occupational health hazards and how to construct improved stoves with $94.4 \%$ of them without any training.

\section{Measures employed in preventing/minimizing occupational health hazards}

The majority of respondents $(60.0 \%)$ took some measures to prevent or minimize cuts and bruises,

Table 2. Respondents productivity and purpose of gari production in southern Ghana.

\begin{tabular}{llll}
\hline Variable & & Frequency & Percent \\
\hline \multirow{2}{*}{ Commercial purposes } & Yes & 90 & 100 \\
& No & 0 & 0.0 \\
GP as sole occupation & Yes & 8 & 8.9 \\
& No & 82 & 91.1 \\
& $<100$ & 2 & 2.2 \\
Average kg of cassava mash & $100-250$ & 30 & 33.3 \\
processed in a week & $300-450$ & 28 & 31.1 \\
& $500-650$ & 23 & 25.6 \\
& $750-850$ & 4 & 4.4 \\
\hline
\end{tabular}

GP = Gari Production 


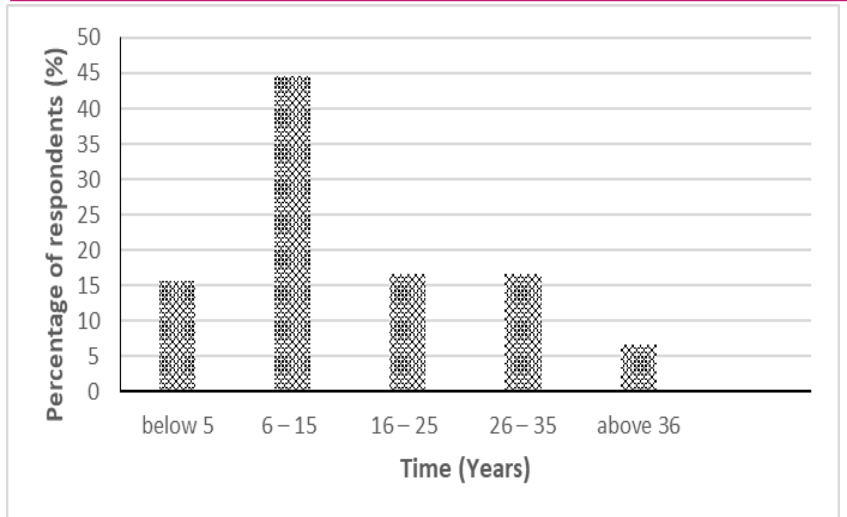

Fig. 1. Years of experience of respondents in gari production in southern Ghana.

while $37.8 \%$ did not take any measure. Only $5.6 \%$ of respondents used strong and secured ropes around the fingers to prevent cuts and bruises while 12.2 used less sharp knives to prevent cuts. To prevent skin irritations, only $16.7 \%$ of the respondents indicated they wear protective cloths. The majority $(68.9 \%)$ of them did not take any measure to prevent skin irritation with $18.9 \%$ of them taking some caution. The majority of respondents $(58.9 \%)$ employed no measure to prevent or minimize smoke inhalation from the furnace during processing. Only $17.8 \%$ seat behind a high mud wall partitioning the processor and furnace, while $10 \%$ of the respondents indicated they take time off during production to prevent or minimize smoke inhalation. Similarly, the majority of gari producers $(45.6 \%)$ take a high level of caution and attentiveness as a means of preventing or minimizing burns. A few gari producers (4.4\%) placed rags at the rim of the pan in order to prevent or minimize burns. Only $8.9 \%$ of respondents regularly took breaks or run shifts (to manage fatigue) to minimize burns.

\section{Factors influencing processors' awareness of protective clothing}

The majority of the respondents (68.9\%) had no awareness of protective equipment as applicable to their work, with only $31.1 \%$ having awareness. Table 3 presents probit regression results to determine factors that influence processors' awareness of wearing protective equipment when processing cassava into gari. From the Table, education, knowledge of hazardous of gari processing, training on occupational health hazard and a visit to health facility relating to condition sustained at work influence awareness of wearing protective equipment. The pseudo $R^{2}$ of 0.401 implied that the independent variables jointly influenced $40.1 \%$ of the variation that occurred in the dependent variable (processors awareness of protective clothing) in the model.

The education of gari producers significantly $(p<0.01)$ influenced the awareness of wearing protective equipment (PPE) during processing. The result implies that the probability of a processor being aware of PPE during processing increases education attainment. A processor's education increases his/her knowledge about the harmful effects of exposure to heat for long hours and cassava effluent containing cyanide. For each additional educational level, individuals were $3.8 \%$ more likely to be aware of protective equipment. Processors with knowledge of hazardous of gari production were $36.7 \%$ more likely to be aware of wearing protective equipment. Processors who had training on occupational health hazards associated with gari production were

Table 3. Factors influencing processors awareness of protective clothing in southern Ghana.

\begin{tabular}{llll}
\hline Variable & Coefficient & P-value & Marginal Effect \\
\hline Gender & 0.297 & 0.359 & 0.097 \\
Age & -0.216 & 0.513 & -0.071 \\
Education & 0.027 & $0.004^{* *}$ & 0.038 \\
Length of gari production & 0.091 & 0.490 & 0.030 \\
Knowledge of hazardous of gari pro- & 1.812 & $0.003^{* *}$ & 0.367 \\
cessing & 0.291 & $0.031^{*}$ & 0.134 \\
Training on occupational health hazards & $0.019^{*}$ & 0.115 \\
Visit to health facility relating to condition & 0.353 & 0.089 & \\
sustained at work & -1.103 & & \\
Constant & & & \\
Regression Diagnostics & -46.701 & & \\
Log likelihood & 0.401 & & \\
Pseudo $\mathrm{R}^{2}$ & 18.20 & & \\
LR chi $^{2}(7)$ & 0.011 & & \\
Prob> chi & & & \\
\hline
\end{tabular}

*indicates $5 \%$ significance level; **indicates $1 \%$ significance level 
$13.4 \%$ more likely to be aware of protective equipment. Similarly, those who had ever visited a health facility concerning a health condition sustained at work were $11.5 \%$ more likely to be aware of protective equipment.

\section{Factors influencing the wearing of protective equipment}

For personal protective equipment (PPE), only $3.3 \%$, $16 \%$, and $17.8 \%$ used footwear, working gear and coat, respectively (Table 4 ) during production. Table 9 presents probit regression results to determine factors that influence gari producers' decision to wear protective equipment. From the Table, years of processing experience, knowledge of health risk associated with gari production, awareness of protective equipment and visit to health facility relating to condition sustained at work had a positively significant $(p<0.01)$ influence on wearing of PPE during the processing of cassava into gari. However, training on occupational health hazards negatively influenced the wearing of PPE. Location, gender, education and age did not influence the wearing of PPE by processors. For each increase in experience in gari production, processors were $2.4 \%$ more likely to wear PPE. The result implies that the probability of gari producers using PPE increases with an increase in years of experience in gari production.

Processors with knowledge of hazards associated with gari production were $5.5 \%$ more likely to use protective equipment. The result implied that the probability of a processor using PPE during gari production increases with knowledge of cassava processing hazards. Knowledge of health hazards will motivate wearing of protective equipment during processing. Similarly, awareness of protective equipment was $6.5 \%$ more likely to increase its use. Respondents who visited a health facility in relation to health condition related work were $11.7 \%$ more likely to wear PPE. However, individuals who had training on occupational health hazards associated with gari production were $9.8 \%$ less likely to use PPE. Respondents reported health conditions such as dizziness, induced fever, severe aches and pains, induced diarrhea, deep cuts, boulder accident, eye irritation and skin rashes, of which they sought health care.

\section{Environmental hazards associated with cassava effluent}

The majority $(80 \%)$ of respondents discharged their effluent into the environment. None of the respondents treated their effluent before discharge. About $20 \%$ of respondents kept their effluent for later use. Some environmental effect of the effluent reported by the respondents included bad odour (87.8\%), destruction of vegetative cover where effluent is discharged $(96.7 \%)$, death of some trees $(10 \%)$ and loss of soil productivity $(43.3 \%)$. Out of the $20 \%$ of processors who kept their effluents for later use, $66.7 \%, 66.7 \%$ and $50 \%$ utilized the effluent in weed control, tapioca (dried white flakes) making and starch, respectively. About $8.1 \%$ and $5.5 \%$ used it in making cassava biscuit and chalk, respectively.

\section{Factors that influencing processors' decision to keep the effluent for later use}

Table 5 presents probit regression results to determine factors that influence processors' choice to keep the

Table 4. Factors influencing the wearing of protective equipment in southern Ghana.

\begin{tabular}{llll}
\hline Variable & Coefficient & P-value & Marginal Effects \\
\hline Location & -0.066 & 0.812 & -0.003 \\
Gender & -0.403 & 0.430 & -0.158 \\
Age & -0.168 & 0.440 & -0.007 \\
Education & -0.047 & 0.836 & -0.002 \\
Experience in gari production & 0.624 & $0.002^{* *}$ & 0.024 \\
Knowledge of gari processing to be hazardous & 15.235 & $0.000^{* *}$ & 0.055 \\
Training on occupational health hazards & -16.420 & $0.000^{* *}$ & -0.098 \\
Awareness of protective equipment & 1.235 & $0.006^{* *}$ & 0.065 \\
Visit to health facility relating to condition sus- & 0.906 & $0.010^{* *}$ & 0.117 \\
tained at work & -17.862 & 0.000 & \\
Constant & & & \\
Regression Diagnostics & -37.243 & & \\
Log pseudolikelihood & 1148.08 & & \\
Wald chi ${ }^{2}$ (9) & 0.000 & & \\
Prob> chi & & & \\
\hline
\end{tabular}

**indicates $1 \%$ significance level 
effluent for later use. The pseudo $\mathrm{R}^{2}$ of 0.303 indicated that $30.3 \%$ of the variation in the dependent variable (effluent kept) was jointly influenced by the model's independent variables. The empirical results showed that location, experience in cassava processing, observed effects of effluent discharge on the environment, and awareness of value addition significantly $(p<0.05)$ and positively influenced processors decision to keep effluent for later use. Gari producers located in Central Tongu were $8.7 \%$ more likely to keep the cassava effluent for later use than respondents from other locations. With an increase in years of experience in cassava processing into gari, processors were $8.2 \%$ more likely to keep the effluent for later use. Respondents who had observed the untreated effluent's environmental effects were $15.1 \%$ more likely to keep the effluent. Similarly, processors with an awareness of value-added options for the effluent were $18.1 \%$ more likely to keep the effluent.

\section{DISCUSSION}

The higher number of females than males in the gari production industry could be attributed to that fact that women play a principal role in food processing and the wholesomeness of food (Obeng-Ofori and Boateng, 2008). This is in line with the findings of Quaye et al. (2009), who reported an average of $94.5 \%$ female involvement in cassava processing and the result of Mensah et al. (2020), who reported that about $98 \%$ of female farmers carried out hauling of crops in semi-arid
Ghana. This high percentage of female involvement could largely be explained by the Ghanaian society's firmly rooted perception of food handling (processing and cooking) to be the responsibility of the female, as seen in many Ghanaian homes and eateries (Akabanda et al., 2017).

The majority of the respondents are within the most active years $(30-49)$ of life. This might be due to the labour-intensive nature of cassava processing and high exposure to health hazards, hence less attractive to people above 50 years (Adenugba and John, 2014). In advanced age, tolerance to health risk conditions was minimal, which suggested the low involvement of people with age group $\geq 50$ years as argued by Yidana et al. (2013). The finding in this study was in line with Akabanda et al., (2017), who reported in research conducted that only $20 \%$ of people within this age group are involve in food processing and handling.

Higher education level is reported to have a link with access to information on improved technologies and production challenges (Paltasingh and Goyari 2018) and health. Many studies showed a positive relationship between the education level of the household head and the adoption of improved technologies (Danso-Abbeam et al., 2017; Deressa et al., 2009). Bello et al.(2013) argued that low-level education of cassava processors had implications on adopting modern technology. Conversely, the section of respondents who had higher-level education indicated likely ease of understanding of information. This educated group could serve as focal points in disseminating information

Table 5. Probit results on factors influencing processors' decision to keep effluent for later use.

\begin{tabular}{|c|c|c|c|}
\hline Variable & Coefficient & P-value & Marginal Effect \\
\hline Location (Central Tongu) & 0.426 & $0.047^{*}$ & 0.087 \\
\hline Gender & 0.716 & 0.174 & 0.145 \\
\hline Age & -0.166 & 0.420 & -0.034 \\
\hline Education & 0.276 & 0.118 & 0.056 \\
\hline Experience in cassava processing & 0.404 & $0.029^{*}$ & 0.082 \\
\hline $\begin{array}{l}\text { Observed effects of effluent discharge on } \\
\text { the environment }\end{array}$ & 0.745 & $0.042^{*}$ & 0.151 \\
\hline Awareness of value addition options & 1.012 & $0.020^{*}$ & 0.181 \\
\hline Constant & -4.097 & 0.013 & \\
\hline \multicolumn{4}{|l|}{ Regression Diagnostics } \\
\hline Log likelihood & -31.414 & & \\
\hline Pseudo $\mathrm{R}^{2}$ & 0.303 & & \\
\hline $\operatorname{LR}_{\text {chi }^{2}}(7)$ & 27.24 & & \\
\hline Prob> chi ${ }^{2}$ & 0.0003 & & \\
\hline
\end{tabular}

*indicates $5 \%$ significance level 
to individuals of a lower education level or no education.

The low number of gari producers receiving training indicated that the stakeholder institutions had not given much attention to address issues of occupational safety and health $(\mathrm{OSH})$. Comparatively, much effort has been geared towards equipping farmers and processors with improved cassava varieties to maximize their outputs and profits (as with the Root and Tuber Improvement Programme [RTIP]) (Quaye et al., 2009), while issues of occupational safety and health seem marginalized.

The diverse responses given by the processors concerning measures they employ to prevent or minimize the occurrence of health hazards points to the fact that gari producers are aware of some dangers they are exposed. The high percentage of respondents with 'no measures' in minimizing the health hazards suggests that stakeholder institutions have done little in disseminating appropriate information to mitigate health risks. The Processors who took some measures such as putting rags at the rim of the pan in order to prevent or minimize burns regularly took breaks or run shifts attested that the measures were effective in minimizing the intensity of the hazards or risks. This finding was in line with Adenugba and John (2014) findings which reported that gari producers attributed some hazards such as cuts to bad attitude to work.

None of the respondents made use of hand gloves and nose masks. This was in contrast with Adepoju1 et al. (2019) findings which reported that $76 \%$ of the gari producers often used overall during gari frying to prevent skin irritation in Oyo State, Nigeria. Respondents attributed the less usage of the overall working gear and coat to considerable discomfort they experienced when using them. The high atmospheric temperature, coupled with intense heat emanating from the furnace, hindered the frequent usage of this PPEs. However, the usage mitigated the skin irritations experienced when cyanide-laden cassava mash comes in contact with the skin and burns. Lucas et al.(2014) reported that heavy physical workloads and/or protective equipment create strenuous and potentially dangerous thermal loads for the worker during hot and humid climatic conditions. Hot and humid conditions create a thermal heat extreme as heat loss from the body to the environment becomes increasingly difficult (Lucas et al., 2014). Bishop et al. (2013) also reported that thermal comfort was key in using protective equipment.

The result implied that the probability of gari producers using PPE increased with increased years of experience in gari production. This result is in line with the finding of Okoffo et al. (2016), who reported an influence (but negative) of years of farming experience on wearing of protective equipment by cocoa farmers in
Ghana. Processors with knowledge of hazards associated with gari production were $5.5 \%$ more likely to use protective equipment. The result implied that the probability of a processor using PPE during gari production increases with knowledge of cassava processing hazards. Knowledge of health hazards will motivate the wearing of protective equipment during processing. The effluent's environmental effect such as bad odour, destruction of vegetative cover where effluent is discharged, death of some trees, and loss of soil productivity reported by the respondents might be due to the high content of cyanide.

\section{Conclusion}

It can be concluded from the findings of the above study that gari producers were aware of the health risks associated with the industry. However, very few of them took measures to reduce or mitigate exposure to health risk and reduce cassava effluent's environmental impact. These can be attributed to processors lack of technical knowledge and inadequate training on safety measures. Women highly dominated the gari production industry in Ghana. Due to the labour-intensive nature and exposure to health risks, the involvement of older people (above 60 years) is low. Training and education on occupational safety and health risk and the usage of PPEs were low. Some of the environmental effects of mill cassava effluent identified by the gari producers were; reduction in soil productivity, destruction of vegetation cover, the killing of trees and bad odour. However, most processors did not treat effluents before discharge into the environment. Only $20 \%$ of the processors added value to the effluent. Stakeholder institutions should provide training on occupational safety and health $(\mathrm{OSH})$ and guidelines relating to cassava wastewater treatment and discharge.

\section{ACKNOWLEDGEMENTS}

The authors thank Mr. Jawula A. Tahiru and Mr. Samuel Yeboah, of MoFA Awutu Senya and Ayensuano Agencies respectively, and Ms. Victoria Agbeko of Mafi Kpedzeglo D/A School for their assistance during data collection. We also thank Mr. K.A. Asante and Mr. Adu Ofori, both of WRI, and Amoako Ofori for their support.

\section{Conflict of interest}

The authors declare that they have no conflict of interest.

\section{REFERENCES}

1. Adenugba, A. A. and John, P. (2014). Hazardous Conditions Of Women In Gari Processing Industry In Ibadan, South West, Nigeria. Journal of Educational and Social 
Fosu-Mensah, B. Y. et al. / J. Appl. \& Nat. Sci. 13(1): 230 - 237 (2021)

Research, 4(3), 511-521. doi:10.5901/
jesr.2014.v4n3p511

2. Adepoju, A. A., Oladeebo. J. O. and Toromad, A. S. (2019). Analysis of Occupational Hazards and Poverty Profile among Cassava Processors in Oyo State, Nigeria. Asian Journal of Advances in Agricultural Research, 9(1), $1-13$

3. Akabanda, F., Hlortsi, E. H. and Owusu-Kwarteng, J. (2017). Food safety knowledge, attitudes and practices of institutional food-handlers in Ghana. BMC Public Health 17 (40), 1-9. DOI 10.1186/s12889-016-3986-9

4. Akpokodje, O. I., Uguru, H. and Esegbuyota, D. (2018). Remediation of Cassava Effluent Contaminated Soil Using Organic Soap Solution: Case Study of Soil Physical Properties and Plant Growth Performance. Journal of Scientific Research and Reports. 21(3): 1-11, JSRR.45048 ISSN: 2320-0227

5. Bello, M., Ejembi E. P., Allu, E. and Anzaku, T. A. K. (2013). Rural Women Processing Cassava in Doma Local Government Area of Central Nigeria Deserve Technical Assistance. Research on Humanities and Social Sciences, 3(10), 105-112.

6. Bishop, P. A., Balilonis, G., Davis, J. K. and Zhang, Y. (2013) Ergonomics and Comfort in Protective and Sport Clothing: A Brief Review. J Ergonomics. S2: 005. doi:10.4172/2165-7556.S2-005

7. CCOHS (Canadian Centre for Occupational Health and Safety) (2014). OSH Answers Fact Sheets. Hot Environments - Health Effects and First Aid. Retrieved July 9, 2015, from http://www.ccohs.ca/oshanswers/phys_agents/ heat_health.html

8. Danso-Abbeam, G. Antwi Bosiako, J., Ehiakpor, D. S. and Mabe, F. N. (2017) Adoption of improved maize variety among farm households in the northern region of Ghana. Cogent Economics and Finance, 5(1), 1-14

9. Deressa,T. T., Hassan, R. M., Ringler, C., Alemu, T. and Yesuf, M. (2009). Determinants of farmers' choice of adaptation methods to climate change in the Nile Basin of Ethiopia. Global Environmental Change, 19, 248-255

10. Frca, P. G. and Frca Fficm, R. V. M. (2015). Smoke inhalation injury. BJA Education, 15 (3): 143-148

11. Graham, J. and Traylor, J. (2020). Cyanide toxicity. StatPearls Publishing, Treasure Island (FL), 2 July 2020, PMID: 29939573. ,https://europepmc.org/article/NBK/ NBK507796

12. James, B., Okechukwu, R., Abass, A., Fannah, S., Maziya -Dixon, B., Sanni, L., Osei-Sarfoh, A., Fomba, S. and Lukombo, S. (2012). Producing Gari from Cassava: An illustrated guide for smallholder cassava processors. International Institute of Tropical Agriculture (IITA): Ibadan, Nigeria.

13. Juntarawijit, Y. and Juntarawijit, C. (2019) Cooking smoke exposure and respiratory symptons among those responsible for household cooking: A study case in Phitsanulok, Thailand. Heliyon 5; 1-7.
14. Lucas, R. A. I., Epstein, Y. and Kjellstrom, T. (2014). Excessive Occupational Heat Exposure: A Significant Ergonomic Challenge and Health Risk for Current and Future Workers. Extreme Physiology and Medicine, 3(14), 1-8

15. Mensah, M., Vlek, P. L. G., Fosu-Mensah, B. Y. (2020). Agriculture and gender roles in the semi-arid region of Ghana. West Africa Journal of Applied Ecology, 28(1), 144-157

16. Morgan, N. K. and Choct, M. (2016). Cassava: Nutrient composition and nutritive value in poultry diets. Animal Nutrition, 2, 253-261.

17. Neghab, M., Delikhoon, M., Baghani, A. N., Hassanzadeh, J. (2017). Exposure to Cooking Fumes and Acute Reversible Decrement in Lung Functional Capacity. International Journal of Occupational and environmental Medicine 8(4), 1-5

18. Obeng-Ofori, D. and Boateng, B. A. (2008). Global Population Growth, Crop Losses and Postharvest Technology. In E. W. Cornelius and D. Obeng-Ofori (Eds.), Postharvest Science and Technology 1-46. Accra: Smartline Publishing Limited.

19. Obueh, H. O. and Odesiri-Eruteyan, E. (2016). A Study on the Effects of Cassava Processing Wastes on the Soil Environment of a Local Cassava Mill. J Pollut Eff Cont 4 (4). DOI: 10.4176/2375-4397.1000177.

20. Ogunyinka, O. and Oguntuase, A. (2020). Analysis of cassava production and processing by various groups in support of cassava value chain in the south west of Nigeria. ISABB. J. Food Agric. Sci. 9(1), 11-19, DOI: 10.5897/ ISABB-JFAS2020.0113

21. Okoffo, E. D., Mensah, M. and Fosu $\square$ Mensah, B. Y. (2016). Pesticides exposure and the use of personal protective equipment by cocoa farmers in Ghana. Environ Syst Res 5(17), 1-15

22. Omotosho, O. and Amori, A. (2015). Caustic Hydrogen Peroxide Treatment of Effluent from Cassava Processing Industry: Prospects and Limitations. International Journal of Engineering and Technology Innovation, 5 (2), 121-131

23. Oyinkan, A. O., Poku, A., K. and John-Baptiste, A. (2016) The Fire Under the Shed: The Cornerstone Fuelling Our Plight. In: Terry, A.L. and John-Baptiste, A. [eds] Western Public Health Casebook. London, ON: Public Health Casebook Publishing.

24. Paltasingh, K. R. and Goyari, P. (2018). Impact of farmer education on farm productivity under varying technologies: case of paddy growers in India. Agricultural and Food Economics 6 (7), 1-19. doi.org/10.1186/s40100-018-0101-9

25. Quaye, W., Yawson, I., Gayin, J., and Plahar, W. A. (2009). Economic Comparison of Cassava Processing Methods in Some Selected Districts of Ghana , Africa. Journal of Root Crops, 35(2), 211-218.

26. Yidana, J. A., Osei-Kwarteng, M., and Amadu, Y. (2013). The Impact of Cassava Processing on the Livelihoods of Women Processors in Central Gonja District of the Northern Region of Ghana. International Journal of Cassava and Potatoes Research, 1(2), 10-13. 